\title{
Microstructure and Mechanical Properties of Extruded Mg-Sm-Ca Alloys
}

\author{
Chai Yuesheng, Gao Zhigang, Cai Kangle, Fang Daqing
}

Taiyuan University of Science and Technology, Taiyuan 030024, China

\begin{abstract}
Microstructure, age hardening response and mechanical properties of $\mathrm{Mg}-4.0 \mathrm{Sm}-x \mathrm{Ca}(x=0.5,1.0,1.5$, wt $\%)$ alloys extruded followed by isothermal aging at $200{ }^{\circ} \mathrm{C}$ were investigated. The results indicate that with the addition of $\mathrm{Ca}$, the bulk and particle-like $\mathrm{Mg}_{4} \mathrm{Sm}_{5}$ phase containing $\mathrm{Ca}$ and the needle/rod-like $\mathrm{Mg}_{2} \mathrm{Ca}$ phase are formed in the $\mathrm{Mg}$ matrix, grains of the alloy are refined and tensile mechanical properties are improved remarkably. Under T5 (peak-aging) condition, the $\mathrm{Mg}-4.0 \mathrm{Sm}-1.0 \mathrm{Ca}$ alloy shows the smallest grain size of $5.1 \mu \mathrm{m}$. With the increase of $\mathrm{Ca}$ content the amount of $\mathrm{Mg}_{2} \mathrm{Ca}$ phase increases gradually, but that of the bulk Ca-containing $\mathrm{Mg}_{41} \mathrm{Sm}_{5}$ phase, which is mainly distributed at the grain boundaries, decreases obviously when Ca content reaches $1.5 \mathrm{wt} \%$. The peak-aged $\mathrm{Mg}-4.0 \mathrm{Sm}-1.0 \mathrm{Ca}$ alloy exhibits the highest hardness HV (820 MPa) and the optimal ultimate tensile strength, yield tensile strength and elongation of $267 \mathrm{MPa}, 189 \mathrm{MPa}$ and 24\%, respectively. The improved mechanical properties of the alloy are attributed to the grain refinement, the solution strengthening and the precipitation strengthening of $\mathrm{Mg}_{2} \mathrm{Ca}$ phase and $\mathrm{Mg}_{41} \mathrm{Sm}_{5}$ phase.
\end{abstract}

Key words: Mg-Sm-Ca alloy; extruding-aging; microstructure; mechanical property

Magnesium alloys, as the lightest structural materials, have great potential applications in aircraft, automotive industry and transportable equipment due to their excellent properties ${ }^{[1]}$. However, the use of magnesium alloys was restricted in the past owing to their poor mechanical properties and low formability ${ }^{[2-4]}$. Extruded magnesium alloys exhibit superior mechanical properties to as-cast one, due to the refinement of the grains, the elimination of casting defects and the homogenization of microstructure during the plastic deformation processes ${ }^{[5]}$.

It is reported that the addition of rare earth elements (RE) can remarkably improve the mechanical properties of magnesium alloys by a solid solution strengthening and a precipitation strengthening ${ }^{[6,7]}$. It has been found that the $\mathrm{Mg}-\mathrm{Nd}$ alloys exhibit promising mechanical properties ${ }^{[8]}$. Samarium $(\mathrm{Sm})$ belongs to the same subgroup as $\mathrm{Nd}$, and the maximum solid solubility of $\mathrm{Sm}$ in $\mathrm{Mg}$ is $5.7 \mathrm{wt} \%$ at $803 \mathrm{~K}$, which is higher than that of $\mathrm{Nd}(3.6 \mathrm{wt} \%)$ in $\mathrm{Mg}$.
Therefore, it is reasonable to assume that the $\mathrm{Mg}-\mathrm{Sm}$ alloys also exhibit good mechanical properties.

The alkaline earth element $\mathrm{Ca}$ is often added to magnesium alloys to improve the mechanical properties by the grain refinement and precipitation strengthening of the $\mathrm{Mg}_{2} \mathrm{Ca}$ phase ${ }^{[9,10]}$. In addition, Jun et al. ${ }^{[1]}$ investigated that $\mathrm{Ca}$ addition can not only refine the primary $\alpha$-Mg grains but also increase the thermal stability of the $\mathrm{Mg}-\mathrm{RE}$ phases in the Mg-Nd-RE-Ca alloys. Accordingly, it can be concluded that $\mathrm{Ca}$ may play a beneficial role in the improvement of mechanical properties of Mg-Sm based alloys.

Although some $\mathrm{Sm}$ containing magnesium alloys have been developed, the investigation on the effect of $\mathrm{Ca}$ addition on the microstructure and the mechanical properties of $\mathrm{Mg}$-Sm alloys has not been reported yet until now. In the present work, the microstructure and the mechanical properties of $\mathrm{Mg}-4.0 \mathrm{Sm}-x \mathrm{Ca}(x=0.5,1.0,1.5$, $\mathrm{wt} \%$ ) alloys extruded followed by isothermal aging at 200

$\overline{\text { Received date: February 14, }} 2015$

Foundation item: Doctoral Fund of Taiyuan University of Science and Technology (20122011)

Corresponding author: Fang Daqing, Ph. D., Associate Professor, Material Science and Engineering Collage, Taiyuan University of Science and Technology, Taiyuan 030024, P. R. China, Tel: 0086-351-6998126, E-mail: fangdaqingtykd@163.com 
${ }^{\circ} \mathrm{C}$ were investigated, and the corresponding strengthening mechanism was discussed.

\section{Experiment}

The alloy ingots with nominal compositions shown in Table 1 were prepared from high purity $\mathrm{Mg}(>99.95 \%)$ and master alloys of $\mathrm{Mg}-25 \% \mathrm{Ca}(\mathrm{wt} \%$ ) and $\mathrm{Mg}-25 \% \mathrm{Sm}$ (wt $\%$ ) by melting in an electric resistance furnace at about $730{ }^{\circ} \mathrm{C}$ under the mixed gas of $\mathrm{CO}_{2}$ and $\mathrm{SF}_{6}$ with the ratio of 99:1. As-cast ingots with 80 $\mathrm{mm}$ in diameter and $110 \mathrm{~mm}$ in length were homogenized at 500 ${ }^{\circ} \mathrm{C}$ for $24 \mathrm{~h}$ followed by quenching in water of $70 \sim 80{ }^{\circ} \mathrm{C}$, and then were hot extruded at $460{ }^{\circ} \mathrm{C}$ into rods of $16 \mathrm{~mm}$ in diameter with an extrusion ratio of $25: 1$. The aging treatment was carried out at $200{ }^{\circ} \mathrm{C}$ for $170 \mathrm{~h}$ in an electric furnace. In the present experiment, the aging treatment was immediately carried out after extrusion, and the T5 condition means the peak-aged state. Vickers hardness (HV) was measured at the loading force of 100 $\mathrm{g}$ and the holding time of $20 \mathrm{~s}$.

The microstructures of the alloys were examined by an optical microscope (OM, Nikon) and a scanning electron microscope (SEM, S4800) equipped with an energy dispersive X-ray spectrometer (EDS). The metallographic specimens were mechanically polished and etched by immersing for 3 5 $\mathrm{s}$ in a solution of $10 \mathrm{~mL}$ acetic acid, $5 \mathrm{~g}$ picric acid, $10 \mathrm{~mL}$ distilled water, and $85 \mathrm{~mL}$ ethanol. The grain sizes were measured using a linear intercept method in the $\mathrm{OM}$ micrographs. The overall phase constitution analyses were identified by X-ray diffractometer (XRD, Y-2000) with $\mathrm{Cu}-\mathrm{K} \alpha$ radiation. The flat dog-boned specimens for tensile tests had $14 \mathrm{~mm}$ in gauge length and 3 $\mathrm{mm} \times 2 \mathrm{~mm}$ in a cross section. The tensile axis was aligned parallel to the extrusion direction. The tests were conducted on a universal testing machine (Instron1121) at ambient temperature with an initial strain rate of $1.0 \times 10^{-3} \mathrm{~s}^{-1}$. The ultimate tensile strength (UTS), $0.2 \%$ yield strength (YS) and elongation to fracture were obtained based on the average value of three tests.

\section{Results and Discussion}

\subsection{Effects of Ca on microstructure}

Fig.1 shows the optical micrographs of alloys as the extruded state and the peak-aged state. The alloys are mainly composed of equiaxial grains. Compared with the extruded alloy, the average grain size of the peak-aged one increases slightly. The average grain sizes of the alloys as the two states are listed in Table 2.

Fig.2 shows the XRD patterns of the peak-aged alloys. As shown in Fig.2, the alloys are mainly composed of $\alpha-\mathrm{Mg}$, $\mathrm{Mg}_{41} \mathrm{Sm}_{5}$ and $\mathrm{Mg}_{2} \mathrm{Ca}$ phases. Furthermore, it is found that the diffraction peaks of the $\mathrm{Mg}_{2} \mathrm{Ca}$ phase are not observed in $\mathrm{S} 1$ alloy. The absence of the $\mathrm{Mg}_{2} \mathrm{Ca}$ phase is ascribed to the relatively small amount of $\mathrm{Ca}$ in $\mathrm{S} 1$ alloy.

As shown in Fig.1, the $\mathrm{Ca}$ content has a great effect on grain size of alloys. Under T5 condition, the average grain sizes of the S1, S2 and S3 alloys are about 10.2, 5.1 and $11.0 \mu \mathrm{m}$, respectively. When the content of $\mathrm{Ca}$ increases to

Table 1 Nominal chemical composition of alloys (wt\%)

\begin{tabular}{cccl}
\hline Alloy & $\mathrm{Sm}$ & $\mathrm{Ca}$ & $\mathrm{Mg}$ \\
\hline S1 & 4.0 & 0.5 & Bal. \\
S2 & 4.0 & 1.0 & Bal. \\
S3 & 4.0 & 1.5 & Bal. \\
\hline
\end{tabular}

Table 2 Average grain sizes of the alloys for different states $(\mu \mathbf{m})$

\begin{tabular}{ccc}
\hline Alloy & Extruded state & Peak ageing state \\
\hline S1 & 8.6 & 10.2 \\
S2 & 4.2 & 5.1 \\
S3 & 9.1 & 11.0 \\
\hline
\end{tabular}

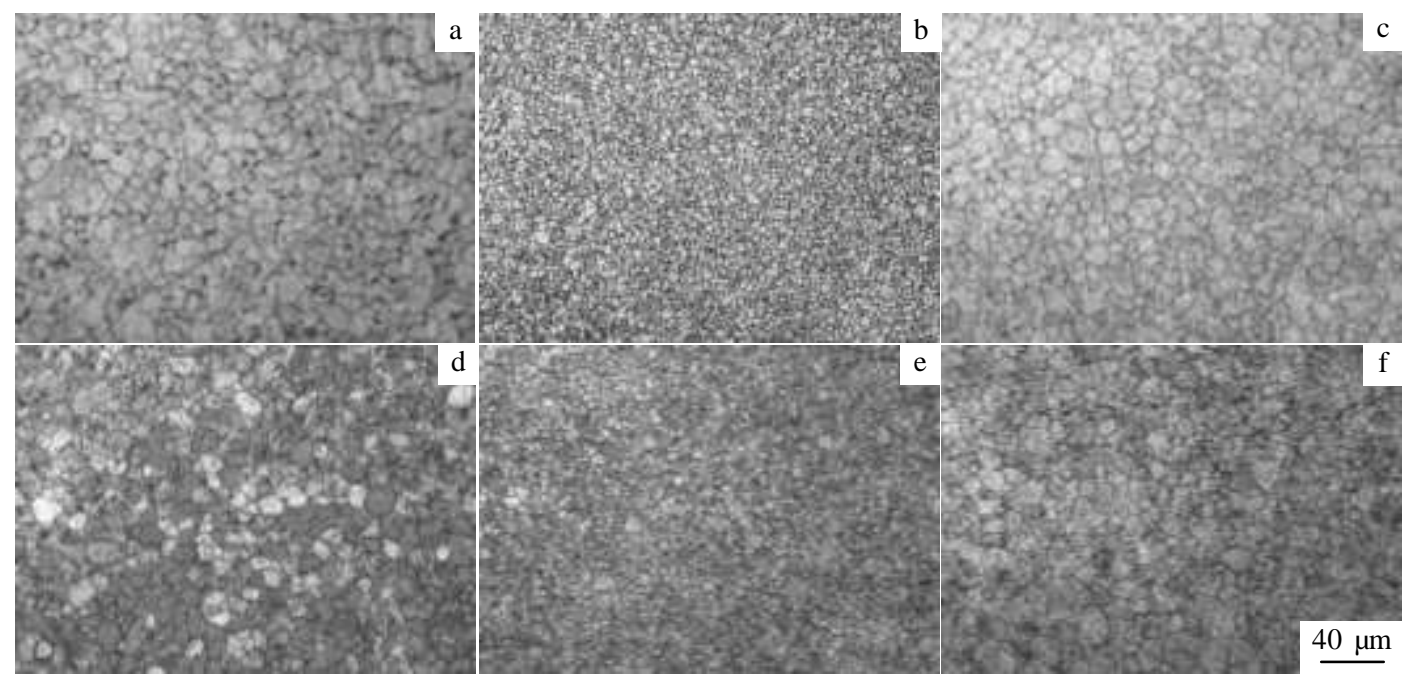

Fig.1 Optical micrographs of Mg-Sm-Ca alloys: (a) S1 alloy as extruded state, (b) S2 alloy as extruded state, (c) S3 alloy as extruded state, (d) S1 alloy as peak aged state, (e) S2 alloy as peak aged state, and (f) S3 alloy as peak aged state 


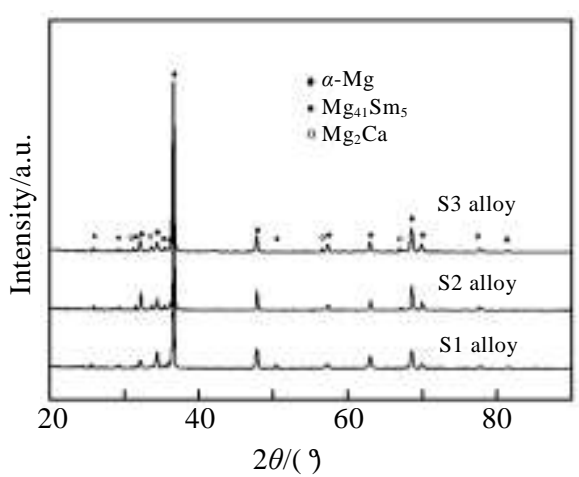

Fig.2 XRD patterns of $\mathrm{Mg}$-Sm-Ca alloys as peak aged state

$1.0 \mathrm{wt} \%$, the alloy shows the smallest grain size (Fig.1e). According to the classic solidification theory, the relationship between the critical nucleus radius and the undercooling degree are given as follows ${ }^{[12]}$ :

$$
r^{*}=\frac{2 \sigma}{\Delta G_{\mathrm{r}}}=\frac{2 \sigma T_{\mathrm{m}}}{L_{\mathrm{m}} \Delta T}
$$

where $r^{*}$ is the critical nucleus radius, $\Delta G_{\mathrm{r}}$ is the variation of volume free energy, $\sigma$ is the interfacial energy of unit surface area, $T_{\mathrm{m}}$ is the equilibrium crystallizing temperature, $L_{\mathrm{m}}$ is the crystallizing latent heat and $\Delta T$ is the undercooling degree.

According to Eq.(1), the critical nucleus radius decreases with the increasing of $\Delta T$, then the nucleation energy of crystal nucleus reduces and the probability of nucleation increases, which results in the grain refinement. As a surface active element, $\mathrm{Ca}$ tends to segregate in the melt alloy to form intensive constitutional undercooling ahead of solid/liquid interface in diffusion layer, which promotes nucleation and restrains the growth of $\alpha-\mathrm{Mg}$ grains, thus causing the grain refinement.

However, when the addition of $\mathrm{Ca}$ increases to $1.5 \mathrm{wt} \%$, the grains become coarser and the average grain size reveals a significant increase, as shown in Fig.1f. The SEM images of the peak-aged alloys are shown in Fig.3. It is found that the alloys are composed of $\alpha-\mathrm{Mg}$ and dispersively distributed intermetallic precipitates. The second phases (Fig.3) are identified by the XRD results (Fig.2) and the EDS analysis (Table 3). The EDS analyses reveal that some $\mathrm{Ca}$ atoms dissolve into the $\mathrm{Mg}_{41} \mathrm{Sm}_{5}$ phases and the volume fraction of $\mathrm{Ca}$ atoms increases significantly with increasing of $\mathrm{Ca}$ content. As shown in Fig. 3a, the bulk and particle-like phases in $\mathrm{S} 1$ alloy is the $\mathrm{Mg}_{41} \mathrm{Sm}_{5}$ phase containing $\mathrm{Ca}$. With $\mathrm{Ca}$ content increases from $0.5 \mathrm{wt} \%$ to $1.0 \mathrm{wt} \%$, some needle/rod-like $\mathrm{Mg}_{2} \mathrm{Ca}$ phase is observed in S2 alloy. In addition, the distribution of $\mathrm{Mg}_{41} \mathrm{Sm}_{5}$ phase is more uniform. However, the bulk shaped Ca-containing $\mathrm{Mg}_{41} \mathrm{Sm}_{5}$ phase which is distributed at the grain boundaries exhibits a significant decrease in S3 alloy, while the $\mathrm{Mg}_{2} \mathrm{Ca}$ phase and particle-like $\mathrm{Mg}_{41} \mathrm{Sm}_{5}$

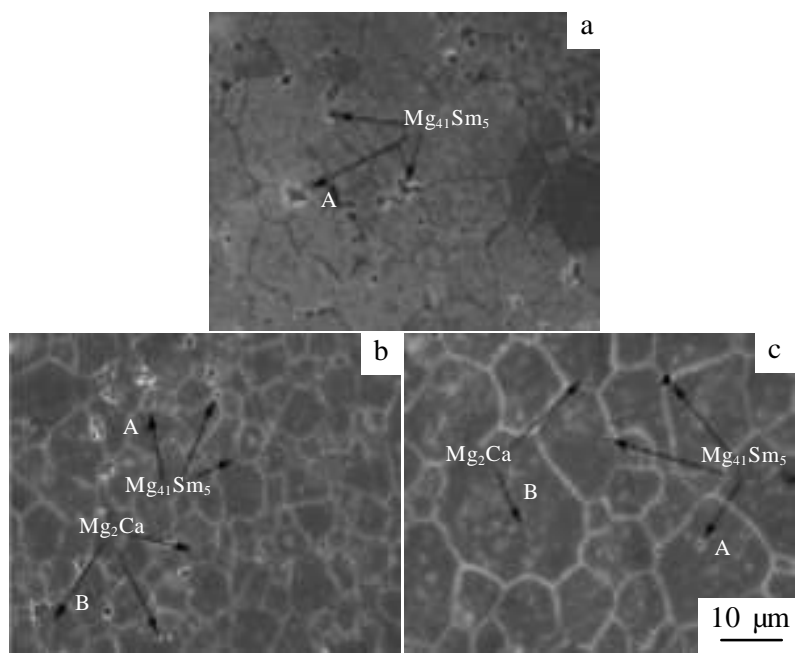

Fig.3 SEM images of $\mathrm{Mg}-\mathrm{Sm}-\mathrm{Ca}$ alloys as peak aged state: (a) S1 alloy, (b) S2 alloy, and (c) S3 alloy

Table 3 EDS results of the experimental alloys in Fig.3 (at\%)

\begin{tabular}{ccccc}
\hline Position & $\mathrm{Mg}$ & $\mathrm{Sm}$ & $\mathrm{Ca}$ & Total \\
\hline Fig.3a-A & 87.72 & 11.77 & 0.51 & 100 \\
Fig.3b-A & 87.14 & 1.53 & 1.33 & 100 \\
Fig.3b-B & 93.42 & 0.84 & 5.74 & 100 \\
Fig.3c-A & 86.97 & 10.16 & 2.87 & 100 \\
Fig.3c-B & 91.71 & 1.13 & 7.16 & 100 \\
\hline
\end{tabular}

phase in the interior of the grains increase. Meanwhile, the $\mathrm{Mg}_{2} \mathrm{Ca}$ phase becomes coarse. The decrease of bulk shaped Ca-containing $\mathrm{Mg}_{41} \mathrm{Sm}_{5}$ phase distributed at the grain boundaries can weaken the dislocation pinning. Therefore, the increase of grain size of S3 alloy is possibly attributed to the weaker pinning effect.

\subsection{Aging characteristics}

Fig. 4 shows the isothermal aging curves of S1, S2, and $\mathrm{S} 3$ alloys aged at $200{ }^{\circ} \mathrm{C}$ for $170 \mathrm{~h}$. The hardness values HV of the three alloys as extruded state are 590, 670 and 630 $\mathrm{MPa}$, respectively. The hardness increases gradually with the increase of aging time, and the peak hardnesses of the three alloys were obtained after aging for $48 \mathrm{~h}$. The peak hardness HV values of the three alloys are 710, 820 and 740 $\mathrm{MPa}$, respectively. The $\mathrm{S} 2$ alloy exhibits the best age-hardening behavior with a maximum peak hardness value of $820 \mathrm{MPa}$. It is suggested that the addition of $\mathrm{Ca}$ can improve the hardness of the alloy. The improved age-hardening behavior of the alloy is attributed to grain refinement strengthening and the increase of the volume fraction of the second phase. However, the excess $\mathrm{Ca}$ addition (1.5 wt $\%$ ) will weaken age-hardening behavior and decrease the peak hardness value.

\subsection{Mechanical properties of the peak-aged alloys}

Fig. 5 shows tensile properties of S1, S2 and S3 alloys as peak-aged state at room temperature. It can be seen that $\mathrm{Ca}$ 


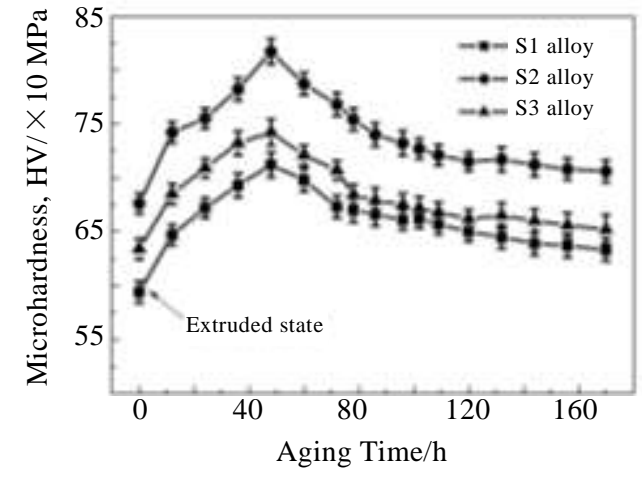

Fig.4 Aging hardening curves of the extruded $\mathrm{Mg}-\mathrm{Sm}-\mathrm{Ca}$ alloys

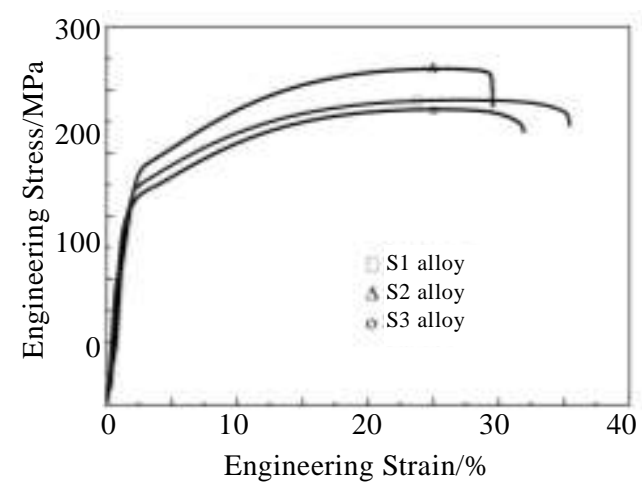

Fig.5 Engineering stress-strain curves of the $\mathrm{Mg}-\mathrm{Sm}$-Ca alloys as Peak-aged state

addition has a significant effect on mechanical properties. The values of UTS, YS and elongation of S1 alloy are 242 $\mathrm{MPa}, 174 \mathrm{MPa}$ and $30 \%$, respectively. The UTS and YS of the alloys increase upon adding $1.0 \mathrm{wt} \% \mathrm{Ca}$, but the elongation decreases. When the Ca content is up to $1.5 \mathrm{wt} \%$, the UTS and YS of the alloys obviously decrease and the values of UTS and YS are $234 \mathrm{MPa}$ and $164 \mathrm{MPa}$, respectively, with an elongation of $26 \%$. The $\mathrm{S} 2$ alloy exhibits the relatively optimal UTS, YS and elongation of $267 \mathrm{MPa}, 189 \mathrm{MPa}$ and 24\%, respectively.

Fig. 6 shows the tensile fracture surfaces of the peak-aged S2 alloy. A great number of dimples and tearing ridges are observed on fracture surface. Some second phase particles are observed within these dimples. These deep dimples, which are associated with the drawing of particles, indicate that a certain amount of plastic deformation is involved prior to rupture. Thus, the fracture mode of peak-aged S2 alloy exhibits a quasi-cleavage with a large amount of dimples.

It is seen from Fig.5 that the tensile strength of the alloy increases when the $\mathrm{Ca}$ content increases from $0.5 \mathrm{wt} \%$ to $1.0 \mathrm{wt} \%$. According to the Hall-Petch relation ${ }^{[13]}$, the grain

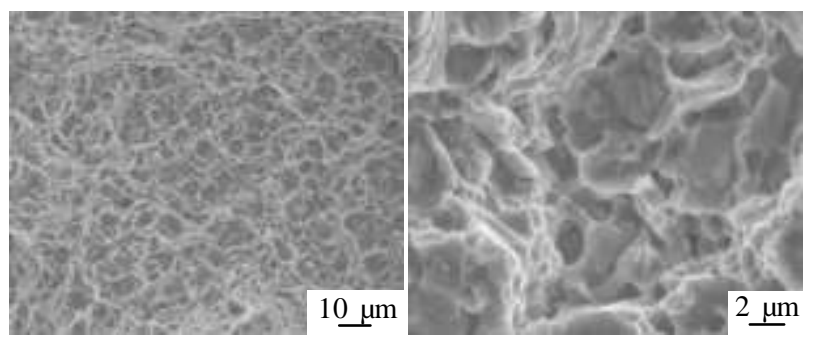

Fig.6 Tensile fracture morphologies of S2 alloy

refinement results in an obvious increase of tensile strength of S2 alloy. The smaller the grain size, the larger the deformation resistance, thus resulting in an increase of the strength. Meanwhile, the increasing of $\mathrm{Mg}_{2} \mathrm{Ca}$ phase will make resistance to the dislocation movement, and thus the tensile strength of S2 alloy is improved. In addition, it was reported that $\mathrm{Ca}$ might also play an important role in enhancing thermal stability of the $\mathrm{Mg}-\mathrm{RE}$ phase [11] However, the $\mathrm{Mg}_{2} \mathrm{Ca}$ phase is a brittle phase, and the decrease of elongation of S2 alloy can be associated with the increase of brittle $\mathrm{Mg}_{2} \mathrm{Ca}$ phase.

Compared with S2 alloy, adding of $1.5 \mathrm{wt} \% \mathrm{Ca}$ brings a detrimental effect on the tensile strength. The decrease of tensile strength can be attributed to the following three factors: (1) The grain size of S3 alloy increases which leads to the decrease of tensile strength. (2) The excess Ca causes the coarsening of $\mathrm{Mg}_{2} \mathrm{Ca}$ phase in the matrix. The presence of these coarse $\mathrm{Mg}_{2} \mathrm{Ca}$ phases promotes the initiation and the propagation of cracks, resulting in an adverse effect on the ultimate tensile strength $^{[14]}$. (3) It was reported that magnesium alloys with the higher $\mathrm{Ca}$ addition are susceptible to hot cracking ${ }^{[15]}$. It can be preliminarily inferred that the reduction of strength by adding $1.5 \mathrm{wt} \% \mathrm{Ca}$ is possibly related to the weakening effect of interfacial micro-cracks associated with the relatively higher hot cracking tendency. However, compared with S2 alloy, the elongation of S3 alloy increases slightly. It is possibly attributed to the weaker pinning effect which is caused by the decrease of bulk $\mathrm{Mg}_{41} \mathrm{Sm}_{5}$ phase distributed at the grain boundaries.

\section{Conclusions}

1) With the $\mathrm{Ca}$ content increases from $0.5 \mathrm{wt} \%$ to 1.0 $\mathrm{wt} \%$, the grains of the alloys are significantly refined. However, excess $\mathrm{Ca}$ addition $(1.5 \mathrm{wt} \%)$ will cause a significant increase of the grain size. The S2 alloy shows the smallest grain size of $5.1 \mu \mathrm{m}$ (under T5 condition).

2) The alloys mainly contain $\alpha-\mathrm{Mg}, \mathrm{Mg}_{41} \mathrm{Sm}_{5}$ phase and $\mathrm{Mg}_{2} \mathrm{Ca}$ phase. The amount of needle/rod-like $\mathrm{Mg}_{2} \mathrm{Ca}$ phase increases gradually with the increase of $\mathrm{Ca}$ content. However, when the Ca content reaches $1.5 \mathrm{wt} \%$, the amount of bulk Ca-containing $\mathrm{Mg}_{41} \mathrm{Sm}_{5}$ phase distributed at the 
grain boundaries decreases significantly and the $\mathrm{Mg}_{2} \mathrm{Ca}$ phase becomes coarse.

3) Adding $1.0 \mathrm{wt} \% \mathrm{Ca}$ to $\mathrm{Mg}-4.0 \mathrm{Sm}$ alloy brings the best age-hardening behavior with the highest peak hardness of $820 \mathrm{MPa}$. The peak-aged S2 alloy exhibits the highest tensile strength. The increase of mechanical properties is mainly attributed to the grain refinement, the solution strengthening and the precipitation strengthening of $\mathrm{Mg}_{2} \mathrm{Ca}$ phase and $\mathrm{Mg}_{41} \mathrm{Sm}_{5}$ phase.

\section{References}

1 Zhou Jixue, Yang Yuansheng, Tong Wenhui et al. Rare Metal Materials and Engineering[J], 2010, 39: 1899 (in Chinese)

2 Bi Guangli, Fang Daqing, Zhao Lei et al. Journal of Alloys and Compounds[J], 2011, 509: 8268

3 Barbagallo S, Cavaliere P, Cerri E et al. Materials Science and Engineering $A[\mathrm{~J}], 2004,367: 9$

4 Li Daquan, Wang Qudong, Ding Wenjiang et al. Transactions of Nonferrous Metals Society of China [J], 2010, 20: 1311

5 Ding Hanlin, Liu Liufa, Kamado S et al. Journal of Alloys and
Compounds[J], 2008, 456: 400

6 Zhang jinghuai, Liu Shunjuan, Leng Zhe et al. Materials Science and Engineering A[J], 2011, 528: 2670

7 Nie J F, Muddle B C. Acta Materialia[J], 2000, 48: 1691

8 Yan Yunqi, Zhang Tiejie, Deng Ju et al. Rare Metal Materials and Engineering [J], 2005, 34(5): 846 (in Chinese)

9 Li Yuncang, Hodgson P D, Wen Cui'e. Journal of Materials Science[J], 2011, 46: 365

10 Fei Houjun, Xu Guanglong, Liu Libin et al. Transactions of Nonferrous Metals Society of China[J], 2013, 23: 881

11 Jun J H, Park B K, Kim J M et al. Key Engineering Materials[J], 2007, 345-346: 557

12 Pan Yichuan, Liu Xiangfa, Yang Hua. Journal of Wuhan University of Technology, Mater Sci Ed[J], 2007, 22: 74

13 Li Mingzhao, Li Cong, Liu Xuguang et al. Rare Metal Materials and Engineering [J], 2009, 38(1): 7 (in Chinese)

14 Wu Guohua, Yu Fan, Gao Hongtao et al. Materials Science and Engineering $A[\mathrm{~J}], 2005,408: 255$

15 John J B, Henry H. SAE Transactions[J], 2000, 109: 574

\title{
挤压态 Mg-Sm-Ca 合金的显微组织和力学性能
}

\author{
柴跃生, 高志刚, 蔡康乐, 房大庆 \\ (太原科技大学, 山西 太原 030024)
}

\begin{abstract}
摘 要: 研究了挤压 $\mathrm{Mg}-4.0 \mathrm{Sm}-x \mathrm{Ca}(x=0.5,1.0,1.5$, mass fraction $\%)$ 合金经过 $200{ }^{\circ} \mathrm{C}$ 等温时效处理后的显微组织、时效硬化行为和力学性 能。结果表明, 随着 $\mathrm{Ca}$ 的添加, 在美基体中形成针/棒状的 $\mathrm{Mg}_{2} \mathrm{Ca}$ 相、块状和颗粒状含 $\mathrm{Ca}$ 元素的 $\mathrm{Mg}_{4} \mathrm{Sm}_{5}$ 相, 合金的晶粒被细化、拉伸力 学性能得到显著提高。在 $\mathrm{T} 5$ (峰值时效) 态下, $\mathrm{Mg}-4.0 \mathrm{Sm}-1.0 \mathrm{Ca}$ 合金具有最细的晶粒, 其大小约为 $5.1 \mu \mathrm{m}$ 。随着 $\mathrm{Ca}$ 含量的增加, 针/ 棒状的 $\mathrm{Mg}_{2} \mathrm{Ca}$ 相逐渐增多, 当 $\mathrm{Ca}$ 含量达到 $1.5 \%$ 时, 晶界处含 $\mathrm{Ca}$ 的块状 $\mathrm{Mg}_{41} \mathrm{Sm}_{5}$ 相的量明显减少。在峰值时效态下, $\mathrm{Mg}-4.0 \mathrm{Sm}-1.0 \mathrm{Ca}$ 合金 具有最大的HV硬度值（820 MPa）以及最佳的力学性能，其抗拉强度、屈服强度和延伸率分别达到了 $267 \mathrm{MPa}, 189 \mathrm{MPa}$ 和 $24 \%$ 。合金 力学性能的提高主要归因于晶粒细化、固溶强化以及 $\mathrm{Mg}_{2} \mathrm{Ca}$ 相和 $\mathrm{Mg}_{41} \mathrm{Sm}_{5}$ 相的析出强化。
\end{abstract}

关键词: Mg-Sm-Ca 合金; 挤压-时效处理; 显微组织; 力学性能

作者简介：柴跃生，男，1959 年生，博士，教授，太原科技大学材料科学与工程学院，山西 太原 030024，电话：0351-6998145 